\title{
Factors Influencing Livelihood Security among the Fishing Migrant Households at Places of Origin in Thailand
}

\author{
Nattapon Meekaew, Dusadee Ayuwat
}

\begin{abstract}
This article examines the factors influencing upon livelihood security among fishing migrant households at their places of origin. The research employed a quantitative approach to the research methodology. Interview schedule was used to collect data from 385 fishing migrant household samples in the Provinces of Surin, Burirum, and Sri Saket, who had members working in the fishing industry for at least one year. Data collection was conducted during April 2018, and descriptive statistics and path analysis were implemented in the data analysis. The results found that a majority of the sampled households had a low-medium level of livelihood security (62.1 percent), while 10.7 percent of the sampled households were observed as having a low level of livelihood security. Path analysis presented factors having a direct effect including land, household assets, human capital, social capital, physical capital, natural capital, and household risks. Factors providing an indirect effect through household risk consisted of year of migration, reason for migration, frequency of remittance received, annual household income, agriculture-based income, none-agriculture income, household assets, social capital, and natural capital, with a statistical significance between the 0.01 level and the 0.05 level. The explanatory variables accounted for 59.38 percent of the variance in explaining livelihood security among the fishing migrant households $(R 2=0.5938)$. Research recommendations focus on livelihood diversification and the mitigating guidelines for the fishing migrant households to reduce risks of livings.
\end{abstract}

Keywords : Livelihood security, households at places of origin, ISAN fishing migrants, livelihoods

\section{INTRODUCTION}

Thailand's policies towards industrial development have produced a huge transition in Thai society. The transitions, caused by modernization, have brought rapid changes to economic, socio-cultural, environmental perspectives, etc. However, these transitions have led to undesired impacts upon Thai society, especially poverty and livelihood vulnerability including such events as natural disasters, climate change, state policies which only focus on urban

Revised Manuscript Received on July 22, 2019

Nattapon Meekaew, Dusadee Ayuwat

$\mathrm{Ph} . \mathrm{D}$. candidate in Sociology, Labour and International Migration Service Center, Faculty of Humanities and

Social Sciences, Khon Kaen University.

Associate Professor, Department of Social Sciences, Division of Sociology and Anthropology, Labour and

International Migration Service Center, Faculty of Humanities and Social Sciences, Khon Kaen University.

Corresponding Author Email: dusayu@kku.ac.th development, and the pursuit of capitalism causing economic inequality within society (Chambers and Conway, 2005). These vulnerabilities severely hit the Thai rural society at rural households have sought ways to combat livelihood insecurity; migration has become one of the livelihood strategies employed by rural households to counter poverty (The World Bank, 2012; Stark, 19991).

Migration has been an ongoing occurrence in Thailand, generally concerning the northeastern or 'ISAN' region, which is recognized as the most populous region in Thailand. Many migrant workers from the northeastern region decided to migrate due to economic reasons. According to National Statistics Office of Thailand (2017), the number of domestic migrants was approximately $8,900,000$ in 2017, and $2,960,000$, or 32.9 percent, were northeasterners. The destinations of the northeastern migrants who have moved for work include the major conurbations such as Bangkok, Chonburi, and Samut Prakan. Many of the migrants have found work in construction and in the services sector, as well as in the marine fishing industry which has been a crucial development mechanism of Thailand since 1967. Many northeastern migrants began working in marine fishery around 1967 , when the industry

received huge promotion from the Thai government through the 2nd National Socio-economic

Development Plan (1967-1971). During recent decades, the number of northeastern migrants employed in the fishing industry has decreased, due to the migration trend turning towards international migration. However, some northeastern migrants have continued working in the fishing industry, although they have become a minority group in the industry, being replaced by international migrants from Burma and Cambodia. In 2017, the Thai government decided to re-organize the fishing industry in response to international concerns. The action by the government has resulted in a significant reduction in the numbers of international migrant workers. Consequently, the northeastern workers have been recruited and have become an important mechanism in driving the Thai fishing industry, once again.

However, the working conditions within the fishing industry carry many risks (Srivirojana et al, 2014). Various illegal activities relating to the fishing industry

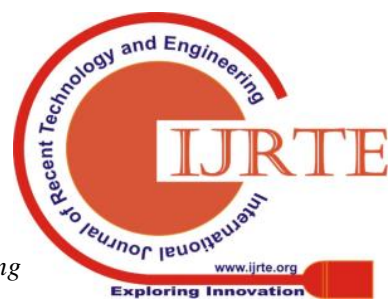


have been reported by numerous international organizations. According to an ILO report (2013) many migrant fishermen are "in danger" from their working conditions. These dangers include, abduction, wage deduction, forced labor, physical and mental abuse, and especially human trafficking, which is a serious problem that affects the Thai fishing industry, internationally (Chantavanich et al., 2016; ILO, 2013).

These problems have a direct impact upon the workers themselves and their households in their places of origin, mostly in the rural northeastern region. These rural households have been recognized as "the left behind households" who share an important role in making the decision to send household members to work in the fishing industry. They then wait for their remittance in order to sustain the households in the origin areas. Moreover, migration to fisheries affects households in the origin areas. Many migrant households have to deal with labor shortages in their production activities (Kassie, 2017, Sundari, 2005), face disputes with neighbors in the community, and even have issues of getting access rights to community benefits (Meekaew and Ayuwat, 2018). These problems cause the fishing migrant households to feel at risk and insecure.

Therefore, this article examines the factors influencing livelihood security among the ISAN fishing migrant households at their places of origin. Implications of the study point out various, livelihood-related, factors that influence the stability of the fishing migrant households and these are beneficial to the relevant agencies. The agencies, such as the Department of Community Development, Ministry of Social Development and Human Security, can benefit from the study when applying development policies for livelihood security to the fishing migrant households in northeastern Thailand.

\section{CONCEPTUALIZING A FRAMEWORK OF LIVELIHOOD} SECURITY

Livelihood Security is an interdisciplinary concept, developed from a range of knowledge regarding livelihoods, which focuses on investigating the barriers people face in living their daily life, especially those who are marginalized (DFID, 2000; Chambers, 1992). Livelihood security has been defined by various scholars. Chambers and Conway (2005) focused on the sufficiency of living resources, i.e. food and cash, which met the basic needs of the households. Drinkwater and Rusinow (1999) defined livelihood security in terms of accessibility and sustainability of living resources that support an individual's needs, such as food, drinking water, medical services, educational opportunity, housing, social relationships,

etc.

The unit of analysis in the livelihood studies is at household level. Chambers and Conway (1991) illustrated the study of livelihoods at household level as "those who conduct activity together". Although household members have the chance to choose their own way of living, some of these ways are still dependent on other household members. However, recent livelihood studies have been conducted using multiple level analyses. Many studies shifted the paradigm from macro-level study to micro-level study, which aimed to investigate at individual level, household level, and community level (Chambers and Conway, 1991; De Haan and Zoomers, 2005, Long and Roberts; 1997).

The development of livelihood security indicators was introduced by CARE, a nonprofit development organization (2004). CARE developed the Household Livelihood Index by categorizing 8 components that are: 1) income and assets, 2) food and nutrition, 3) education, 4) participation, 5) water, 6) sanitation, 7) primary health, and 8) reproductive health (Lindenberg, 2002).

The recent developments of livelihood indicators have prioritized development based on livelihood capital, under a fundamental livelihood concept. Chambers and Conway (1991) began to extend the notion of livelihoods into the study of livelihood security, as did Scoones (1998) who focused on sustainable livelihoods covering various dimensions including, education security, economic security, health security, career security, and empowerment. These dimensions were similar to the definition of livelihood security offered by the World Bank (1990), which attempted to develop livelihood indicators by focusing on diversity and sustainability, especially in economics. Later on, livelihood indicators were developed by linking the economic and social dimensions together, such as the Physical Quality of Life Index (Morris, 1979). The index contributed by exploring the implications for life caused by food quality, drinking water quality, healthcare services, etc. which affected the overall quality of life of the households.

Although recent developments regarding livelihood indicators have focused on development at macro level, several scholars, have shown an increasing interest in developing indicators at micro level. Rahman and Akter (2014) presented indicators of livelihood security that included economics, education, food, healthcare, and the strengthening of the households. Adams and He (1995) offered different indicators. They

considered the interactions between household size, gender, household income, household income distribution, household property, and other household resources. This study determines the factors as: 1) household characteristic factors; number of household members, average age of household members, number of dependent household members, number of migrants, migration year, migration reason, migration method, and frequency of remittance received. 2) Household capital factors; economic capital, human capital, social capital, physical capital and natural capital and 3) household risk factor; household risks. The hypothesis of the study is the household characteristic factors, household capital factors, and household risk factor have an influence on livelihood security among the ISAN migrant households, at their places of origin. 


\section{METHODOLOGY}

The research employed quantitative methodology to examine the factors that influenced the livelihood security of ISAN fishing migrant households. The population of the study is ISAN fishing migrant households in the lower-northeastern region of Thailand, where a large number of fishing migrant households are present. A total of 385 ISAN fishing migrant households, in the Provinces of Surin, Burirum, and Sri Saket, were sampled using Cluster Sampling Technique.

The study identified a dependent variable, which was livelihood security, while independent variables consisted of the number of household members, average age of household members, dependent household members, number of migrants, migration year, migration reason, migration method, frequency of remittance received, economic capital, human capital, social capital, physical capital, natural capital, and household risk.

The research instrument was interview schedule. The interview covered 4 parts that were 1) household characteristics, 2) household capitals, 3) household risks, and 4 ) the livelihood security of the ISAN fishing migrant households. The interview schedule was constructed and a pilot test was conducted with 30 households who had similar characteristics to the sampled households. The interview schedule presented reliability at 0.804 . Data collection was conducted during April 2018, and undertaken with the heads-of-household. The analysis was based at household level, and the research applied descriptive statistics and path analysis to examine the factors that influenced livelihood security of the ISAN fishing migrant households.

\section{RESULT}

The research results comprised three parts: 1) characteristics of ISAN fishing migrant households at the places of origin, 2) livelihood security of ISAN fishing migrant households at the places of origin, and 3) factors influencing livelihood security of ISAN fishing migrant households at the places of origin. Each part is presented as in the following details.

4.1 Characteristics of ISAN fishing migrant households at the places of origin

The results found that the ISAN fishing migrant households at their places of origin were divided into 3 groups that were 1) the good households; households experiencing a good quality of life. Their migrants had good experiences in their fishing work. Their households at the origin areas owned sufficient living resources, for instance, they used the remittance to invest in household production activities, or some households bought land for agriculture

activity, while some saved their remittance at the bank and waited to invest it at some future date. 2) the unsecured households; this household group forms the majority in this study. Although they were able to access livelihood assets, they were always faced with living problems because they could not manage their livelihood assets to generate benefits for the households at the places of origin. For instance, some household members used the remittance for extravagant activities. 3) the struggling households; this household group was considered as a vulnerable group faced with bad life experiences. Their fishing migrant members were exploited by the fishing company, such as by wage deduction, unpaid overtime work, detention, and human trafficking, so they could not send remittance back to their households. Therefore, the households were faced with risks to their livings, and they had to sustain their lives with limited assets, such as compensation provided by a government bureau, or by collecting wild foodstuffs.

The majority of sampled households presented 3 household members (38.7 percent), the average age of household members was between 36-45 years old (39.0 percent), and 80.2 percent of the sampled households lived without any dependent household members. The sampled households sent at least 1 household member to work in the fishing industry ( 92.5 percent), and the migrants had been working in the fishing industry for 4-6 years (37.4 percent). Most of the migrants decided to work in the fishing industry because they wanted to improve the economic status of their households, and 86.9 percent of the sampled households sent their migrants to work with the assistance of cousins or neighbors who had worked in fishing, previously. These individual groups were considered as a social network or a crucial actor in the migration process of ISAN fishing migrants. In addition, the migrants sent remittances to their households every month (77.9 percent).

Identifying the capital utilization for livelihoods among ISAN fishing migrant households at their places of origin, the sampled group utilized human capital (76.9 percent), social capital (79.0 percent), and physical capital (54.0 percent) respectively, considered as being medium level. However, the households utilized natural capital for livelihoods at a low level (47.3 percent) because the communities were mostly located in the Tung Kula Rong Hai area, considered as one of the drought areas of Thailand. The area consists of low quality soil, with drought in the summer season and flooding in the rainy season. These conditions cause low productivity in agricultural activity. These findings confirmed $\mathrm{Su}$ et al (2018), who presented the limitations of access to natural capital. For instance, due to low soil quality, transitions in livings were due to financial capital tending to play a more prominent role in daily life, while the use of natural capital was decreasing.

4.2 Livelihood security of ISAN fishing migrant households at their places of origin

The research results found that the majority of ISAN fishing migrant households had

a low-medium level of livelihood security at their place of origin (62.1 percent). Considering livelihood security by dimensions, the ISAN fishing migrant households had low-medium level of livelihood security in relation to: economic (53.2 percent), health $(59.7$ percent $)$, education (60.5 percent), foods (61.7 percent), and community 
participation (52.7 percent) respectively. It was noticed that the ISAN fishing migrant households had livelihood security of education at a high level (14.5 percent), which was the highest proportion among the various dimensions. Conversely, the ISAN fishing migrant households indicated a low level

for community participation (11.7 percent) and economic security (18.2 percent), the lowest proportion among other dimensions. The findings reflected that fishing activity might not continue to be a suitable option to improve the economic status of the households as in the past. Consumption patterns in modern society caused the households to spend more on household expenses, preventing them from accumulating enough economic capital to develop their households. Moreover, the limitation of land ownership resulted in the households generating only a low, agriculture-based, income. From this it can be concluded that the accumulation of economic assets, such as income or land, was a crucial mechanism that contributed to the households making their living choices, especially in the rural households (Kumar, 2015). In addition, it suggested that the frequency of income received was more important than the amount of income. The households do not require a large amount of income for their living, frequent receipt of income would be sufficient to sustain livelihood security.

An interesting finding indicated that household economic insecurity correlated with the community participation of the households being presented at low level. Currently the ISAN fishing migrant households are still working hard, though they had to sacrifice their community rights and opportunities, for instance, election rights to the community committee, or a right to access community funds. The findings confirmed Kassie's study (2017), which suggested that migration caused labor shortages within the households at their places of origin. When the households required more labor, especially during peak production season, they had to sacrifice opportunities for participating in community activity.

4.3 Factors that influenced on the livelihood security of ISAN fishing migrant households at places of origin

A path analysis was conducted to examine the factors which presented a direct effect

on the livelihood security (LIVSEC) of ISAN fishing migrant households at their places of origin, and the factors which presented an indirect effect on livelihood security among ISAN fishing migrant households at their places of origin through the household risk factor (RISK). The analysis found 7 variables that had a direct effect on livelihood security, as follows:

Land (LAND) had a positive direct effect on livelihood security among ISAN fishing migrant households at their places of origin (beta $=0.161$ ). When the ISAN fishing migrant household had land, every 1 Rai unit would increase livelihood security by 0.161 . The findings confirmed Jaquet (2016), who found that an increase in land ownership among households in Nepal had a direct effect on livelihood diversification, and good land management would increase livelihood security among the households,

especially regarding food security.

Household assets (ASSVL) had a positive direct effect on livelihood security among ISAN fishing migrant households at their places of origin (beta $=0.087$ ). When the ISAN fishing migrant household owned more assets, every 1 unit would increase livelihood security by 0.087 .

Human capital (HUCAP) had a positive direct effect on livelihood security among ISAN fishing migrant households at their places of origin (beta $=0.218$ ). When human capital among the ISAN fishing migrant households increased, each unit would increase livelihood security by 0.218 . The study confirmed Pradipta et al (2015), who found that the accumulation of human capital, i.e. healthy condition of household members, improvement in

working skills, or improvement in language literacy, led households in rural India to have a better quality of life. The households applied the human capital they owned to create income and increase their community participation.

Social capital (SOCAP) had a positive direct effect on livelihood security among ISAN fishing migrant households at their places of origin (beta $=0.521$ ). When social capital among the ISAN fishing migrant households increased, each unit increased livelihood security among them by 0.521 . The fishing migrant households used social capital to overcome limitations in accessing livelihood assets, i.e. sharing farmlands with their relatives, or being a member of local associations. Social capital provided various choices to those who were the marginal ones (Phongsiri and Thongyou, 2012), in this case; the fishing migrant households, to sustain the livings under a tough circumstance they were dealing with.

Physical capital (PHCAP) had a positive direct effect on livelihood security among ISAN fishing migrant households at their places of origin (beta $=0.907$ ). When social capital among the ISAN fishing migrant households increased by 1 unit, the livelihood security among them would increase by 0.907. The findings reflected that the households would have better livelihood security when they were able to access public facilities such as medical services, public water resources, etc. (Mumuni, 2016)

Natural capital (NACAP) had a positive direct effect on the livelihood security among ISAN fishing migrant households at their places of origin (beta $=0.083$ ). When natural capital among the ISAN fishing migrant households increased by 1 unit, livelihood security among them was increased by 0.083 .

Household risks (RISK) had a negative direct effect on livelihood security among ISAN fishing migrant households at their places of origin (beta $=-0.841$ ). When household risks among the ISAN fishing migrant households increased by 1 unit, livelihood security among them would decrease by 0.841 (table 1).

Table 1: An analysis of factors influencing on livelihood security among ISAN fishing migrant households at places of origin 


\begin{tabular}{|c|c|c|c|}
\hline \multirow{2}{*}{ Variables } & \multicolumn{3}{|c|}{ Livelihood Security } \\
\hline & b & Beta & Sig \\
\hline \multicolumn{4}{|l|}{ Migrant characteristic factors } \\
\hline Number of household members (NUHM) & -0.933 & -0.001 & 0.991 \\
\hline Dependent household members (DEPHM) & -0.277 & -0.026 & 0.572 \\
\hline Average age of household members (AGHM) & -0.024 & -0.029 & 0.498 \\
\hline Number of migrants (NUMG) & -0.985 & -0.039 & 0.282 \\
\hline Migrating year (MIGYR) & -0.125 & -0.045 & 0.273 \\
\hline Migrating reason (MIGRE) & -0.343 & -0.017 & 0.646 \\
\hline Migrating method (MIGME) & -0.217 & -0.009 & 0.781 \\
\hline Frequency of remittance received (REMIT) & 1.073 & 0.065 & 0.075 \\
\hline \multicolumn{4}{|l|}{ Livelihood capital factors } \\
\hline Lands (LAND) & 0.244 & 0.161 & $0.005 * *$ \\
\hline Annual household income (INCM) & $-4.79 \mathrm{e}$ & -0.043 & 0.489 \\
\hline Agriculture-based income (AGINC) & -0.000 & -0.074 & 0.208 \\
\hline \multirow{2}{*}{ Variables } & \multicolumn{3}{|c|}{ Livelihood Security } \\
\hline & b & Beta & Sig \\
\hline Non-agriculture income (NOAGINC) & $-6.12 \mathrm{e}$ & -0.036 & 0.504 \\
\hline Savings (SAVI) & $-4.90 \mathrm{e}$ & -0.016 & 0.658 \\
\hline Debts (DEBT) & $-5.60 \mathrm{e}$ & -0.051 & 0.185 \\
\hline Agriculture equipment (AGEQ) & $1.22 \mathrm{e}$ & 0.021 & 0.561 \\
\hline Household assets (ASSVL) & $2.65 \mathrm{e}$ & 0.087 & $0.034 *$ \\
\hline Human capital (HUCAP) & 0.323 & 0.218 & 0.000 \\
\hline Social capital (SOCAP) & 0.523 & 0.521 & 0.000 \\
\hline Physical capital (PHCAP) & 0.243 & 0.907 & $0.024 *$ \\
\hline Natural capital (NACAP) & -0.167 & 0.083 & $0.035^{*}$ \\
\hline Household risk factor (RISK) (Intervening variable) & -0.933 & -0.841 & $0.021 *$ \\
\hline \multicolumn{4}{|l|}{$\mathrm{R}^{2}=0.5938$} \\
\hline
\end{tabular}

The variables which influenced indirectly on livelihood security among the ISAN fishing migrant households at their places of origin, through household risks (the mediator factor), consisted of 9 variables that were 1) migration year (MIGYR) had a negative, indirect effect on livelihood security among the ISAN fishing migrant households, 2) migration reason (MIGRE) had a negative, indirect effect on livelihood security among the ISAN fishing migrant households, 3) frequency of remittance received (REMIT) had a negative indirect effect on livelihood security among the ISAN fishing migrant households,

4) annual household income (INCM) had a negative indirect effect on livelihood security among the ISAN fishing migrant households, 5) agriculture-based income (AGINC) had a positive indirect effect on livelihood security among the ISAN fishing migrant households, 6) non-agriculture income (NOAGINC) had a positive indirect effect on livelihood security among the ISAN fishing migrant households, 7) household assets (ASSVL) had a positive indirect effect on livelihood security among the ISAN fishing migrant households, 8) social capital (SOCAP) had a positive indirect effect on livelihood security among the ISAN fishing migrant households, and 9) natural capital (NACAP) had a positive indirect effect on livelihood security among the ISAN fishing migrant households (table 2).

TABLE 2: THE PATH COEFFICIENT OF DIRECT FACTORS AND INDIRECT FACTORS INFLUENCING ON LIVELIHOOD SECURITY AMONG ISAN FISHING MIGRANT HOUSEHOLDS AT PLACES OF ORIGIN

\begin{tabular}{|c|c|c|c|}
\hline Variables & $\begin{array}{l}\text { Direct } \\
\text { Effect }\end{array}$ & $\begin{array}{c}\text { Indirect } \\
\text { Effect }\end{array}$ & $\begin{array}{l}\text { Total } \\
\text { Effect }\end{array}$ \\
\hline \multicolumn{4}{|l|}{ Household characteristic factor } \\
\hline Migrating year (MIGYR) & & -0.192 & \\
\hline Migrating reason (MIGRE) & & -0.109 & \\
\hline Frequency of remittance received (REMIT) & & -0.118 & \\
\hline \multicolumn{4}{|l|}{ Livelihood capital factor } \\
\hline Lands (LAND) & 0.161 & & \\
\hline Annual household income (INCM) & & -0.206 & \\
\hline Agriculture-based income (AGINC) & & 0.201 & \\
\hline Non-agriculture income (NOAGINC) & & 0.217 & \\
\hline Household assets (ASSVL) & 0.087 & -0.118 & -0.010 \\
\hline human capital (HUCAP) & 0.218 & & \\
\hline Social capital (SOCAP) & 0.521 & 0.155 & -0.080 \\
\hline Physical capital (PHCAP) & 0.907 & & \\
\hline Natural capital (NACAP) & 0.083 & -0.120 & -0.009 \\
\hline Household risk factor (RISK) (Intervening variable) & -0.084 & & \\
\hline Variables & $\begin{array}{l}\text { Direct } \\
\text { Effect }\end{array}$ & $\begin{array}{c}\text { Indirect } \\
\text { Effect }\end{array}$ & $\begin{array}{l}\text { Total } \\
\text { Effect }\end{array}$ \\
\hline
\end{tabular}




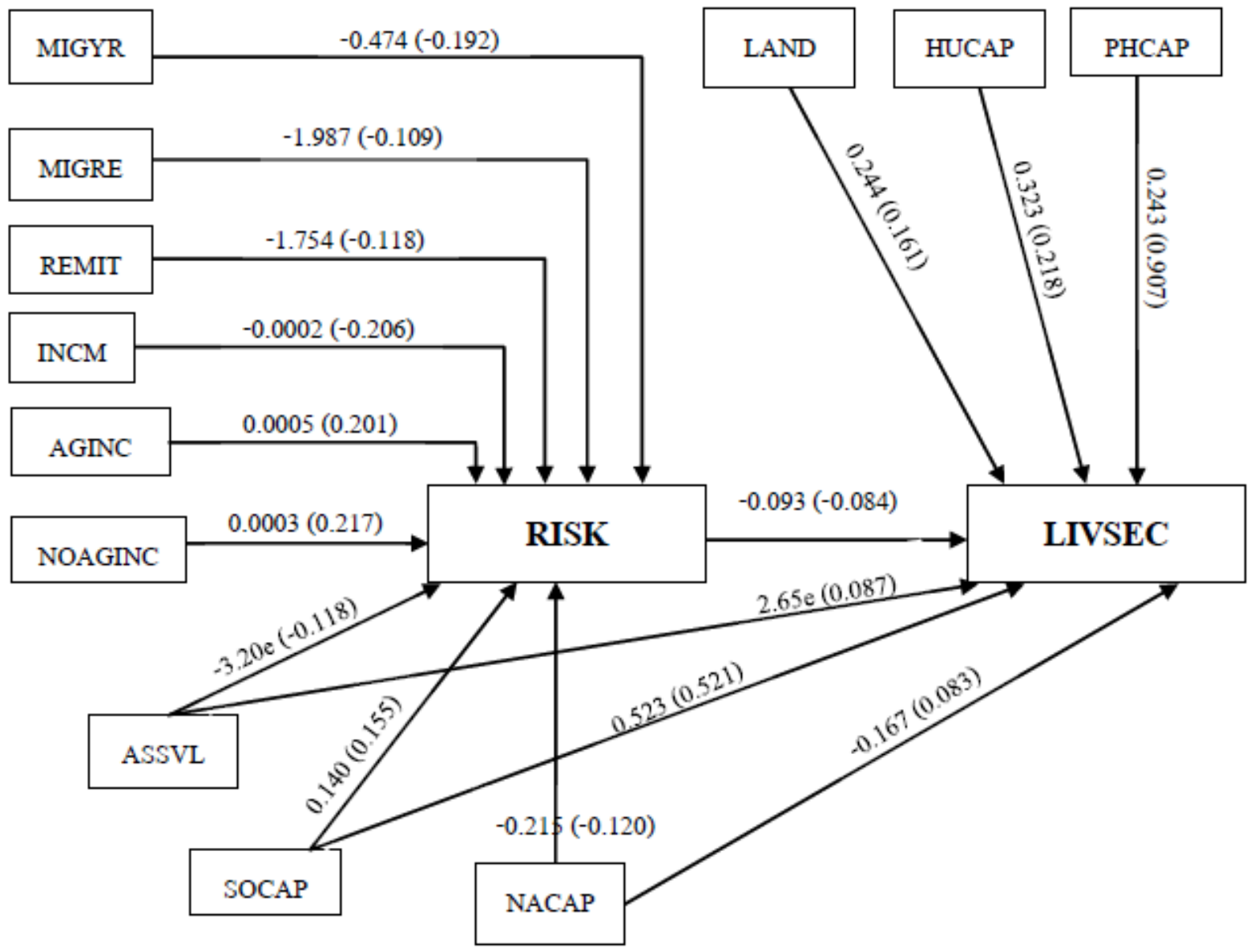

Figure 1: Path model of factors influencing on livelihood security among the ISAN fishing migrant households at places of origin

\section{CONCLUSION AND RECOMMENDATION}

The results found that the factors influencing upon livelihood security among the ISAN fishing migrant households at their places of origin consisted of land, household assets, human capital, social capital, physical capital, natural capital, and household risk. While

factors that show indirect effects, through household risk factors on livelihood security among the ISAN fishing migrant households, consisted of migration year, migration reason, frequency of remittance received, annual household income, agriculture-based income, non- agriculture income, household assets, social capital, and natural capital.

In line with the results, the study recommends that fishing migrant households at their places of origin should implement a variety of livelihood capitals, i.e. economic capital, human capital, social capital, physical capital, and natural capital, in constructing their livelihood strategies at household level. Livelihood diversification should be required to strengthen the sustainability of household security. Local development-related agencies should implement mitigating guidelines for the fishing migrant households, in order to reduce the risks at both household level and community level, for instance, implementing a savings program in the community, providing a training program for occupational skills, providing knowledge of fundamental rights and compensations, etc., in order to create options for the fishing migrant households to deal with any risks that may affect their household security. Finally, the mitigating guidelines should cover a mechanism to identify risks on the fishing activity in order to create awareness among the fishing migrant households and the fishing migrants themselves. This mechanism may be implemented in policies on labour in fishing industry especially the tracking system of fishing migrants to ensure their safety and well- being of their households at origin area.

\section{ACKNOWLEDGEMENT}

This article is a part of Ph.D. Dissertation entitled "Livelihood Security among Households at Places of Origin of ISAN Migrants in Fishing Industry" The authors would like to thank Research and Academic Service, Faculty of Humanities and Social Sciences, Khon Kaen University, and Research and Training Center for Enhancing Quality of Life of Working Age People, Khon Kaen University for their financial support and academic support and all key informants for useful information. 


\section{REFERENCES}

[1] Adams, R.H. and He, J.J. (1995). Sources of Income Inequality and Poverty in Rural Pakistan, Research Report No.102, Washington D.C. International Food Policy Research Institute.

[2] CARE. (2004). Measuring Livelihood Impacts: A Review of Livelihoods Indicators.

[3] Livelihood Monitoring Unit (LMU) Rural Livelihoods Program CARE Bangladesh, Prepared by TANGO International, Inc.

[4] Chambers, R and Conway, G.R. (1991). Sustainable Rural Livelihoods: Practical Concepts for the 21st Century. IDS Discussion Paper 296, IDS (Institute of Development Studies), UK. 33 pp.

[5] Chambers, R. and Conway.G.R. (2005). Ideas for Development. London: Earthscan. Chantavanich, S., Laodumrongchai, S. and Stringer, C. S. (2016). Under the Shadow: Forced

[6] Labour Among Sea Fishers in Thailand, Marine Policy, 68, pp.1-7.

[7] De Haan, L. and Zoomers, A. (2005). Exploring the Frontier of Livelihoods Research.Development and Change. 36(1).

[8] DFID (2000). DFID workshop on indicators for sustainable livelihoods. Report. London:DFID, July 14.

[9] Drinkwater, M., and Rusinow, T. (1999). Application of CARE's livelihoods approach.presentation for NRAC 99.

[10] International Labour Organization. (2013). Employment Practices and WorkingConditions in Thailand's Fishing Sector. Bangkok: ILO.

[11] Jaquet, S., Shrestha, G., Kohler, T., and Schwilch, G. (2016). The Effects of Migration on Livelihoods, Land Management, and Vulnerability to Natural Disasters in the Harpan Watershed in Western Nepal. Mountain Research and Development, 36(4), pp.494-505.

[12] Kassie, G. W., Kim, S., Fellizar, F. P. (2017). Determinant factors of livelihood diversification: Evidence from Ethiopia. Social Sciences, August 2017, retrieved from https://doi.org/10.1080/23311886.2017. 1369490.

[13] Kumar. S., Rohra, C. L., and Lal, K. (2015). Socio-Economic Stability of People through Social Development Projects with Special Focus on Rural Areas of Sindh: A Vision for Prosperity. Pakistan Journal of Commerce and Social Sciences, Vol. 9(1), pp.261-268.

[14] Lindenberg, M. (2002). Measuring Household Livelihood Security at the Family and

[15] Community Level in the Developing World, World Development, 30(2), pp. 301-318.

[16] Long, N. and Roberts, B. (1997). Agency and Constraint, Perceptions and Practices. A Theoretical Position. In H. de Haan and N. Long (Eds.). Images and Realities of Rural Life: Wageningen Perspectives on Rural Transformations. (pp.1-20). Assen: Van Gorcum \& Comp.

[17] Meekaew, N., and Ayuwat, D. (2018). Capital Utilization for Livelihoods among Rural

[18] Fishing Migrant Households in the Origin Area. International Journal of Engineering\& Technology, 7(2.10), pp.86-90.

[19] Mumuni, E., and Oladele, O. I. (2016). Access to Livelihood Capitals and Propensity for Entrepreneurship amongst Rice Farmers in Ghana. Agriculture \& Food Security, 5(1). Retrieved from https://doi.org/10.1186/s40066-015-0049-x

[20] National Statistics Office of Thailand. (2017). The Migration Survey. Retrieved from http://service.nso.go.th/nso/web/survey

[21] Phongsiri, M., \& Thongyou, M. (2012). Thai Diaspora: What Happens When They Return

[22] 'Home'?. Journal of Population and Social Studies [JPSS], 21(1), 59-69. Retrieved https://www.tci-thaijo.org/index.php/jpss/article/view/84513

[23] Pradipta, D., Tapati, B. B., and Subhrangsu, S. (2015). Role of Human Capital for Changing Livelihood Pattern: A Case Study in Nadia District of West Bengal. International Research Journal of Social Sciences, 4(4), pp.98-104.

[24] Rahman, s., and Akter, s. (2014). Determinants of Livelihood Choices: An Empirical Analysis from Rural Bangladesh. Journal of South Asian Development, 9(3).

[25] Srivirojana, N., Punpuing, S., Robinson, C., Sciortino, R., \& Vapattanawong, P. (2014).

[26] Marginalization, Morbidity and Mortality: A Case Study of Myanmar Migrants inRanong Province, Thailand. Journal of Population and Social Studies [JPSS], 22(1),

[27] 33-52. https://www.tci-thaijo.org/index.php/jpss/article/view/102375

[28] Stark, O. (1991). The Migration of Labor. Oxford: Basil Blackwell.

[29] Su, F., Saikia, U., Hay, I. (2018). Relationships between Livelihood Risks and Livelihood

[30] Capitals: A Case Study in Shiyang River Basin, China. Sustainability, 10, pp.1-20.

[31] Sundari, S. (2005). Migration as a Livelihood Strategy: A Gender Perspective. Economic andPolitical Weekly, 40(22), pp.2295-2303.
[32] The World Bank (November 2012). The Migration and Development Brief.Available:http://siteresources.worldbank.org/INPROSPECTS/Res ources/334934-1288990760745/ MigrationDevelopmentBrief19.pdf 